\title{
Melatonin combination with perindopril alleviated doxorubicin cardiac toxicity in L-NAME hypertensive rats: comparative study with perindopril
}

\author{
Takwa Mohammed Abdul Salam, Wesam Mostafa El-Bakly, Ahmed Al-Sayed Badawy, Amany Helmy Hasanin ${ }^{1}$ and \\ Mona Hussein Raafat ${ }^{2}$
}

\author{
${ }^{1}$ Department of Clinical Pharmacology. \\ ${ }^{2}$ Department of Histology. \\ Faculty of Medicine, Ain-Shams University, Cairo, Egypt.
}

\begin{abstract}
Introduction: Doxorubicin is a highly effective anticancer agent with serious cardiotoxic effects. Hypertension is considered as a major risk factor for doxorubicin cardiotoxicity. It should be noted that about one-third of cancer patients have hypertension, and melatonin can have cardio-protective effects. The present study aimed to further investigate the possible beneficial effects of melatonin co-administration to perindopril against doxorubicin cardiotoxicity in hypertensive rats. Method: Rats were randomly assigned to naïve group and $\mathrm{N}$-Omega-Nitro-L-Arginine Methyl Ester Hydrochloride (L-NAME) hypertensive group. L-NAME group was further subdivided into untreated, doxorubicin, doxorubicin / perindopril, doxorubicin/melatonin and doxorubicin/ perindopril / melatonin subgroups. Cardiac functions, CK-MB, malondialdehyde, superoxide dismutase (SOD), tumor necrosis factor- $\alpha$ (TNF- $\alpha$ ), transforming growth factor- $\beta$ (TGF- $\beta$ ), and cardiac percentage area of collagen fibers were evaluated. Results: Combining melatonin with perindopril to doxorubicin produced significant decreases in left ventricular end diastolic pressure, malondialdehyde, TNF- $\alpha$, and TGF- $\beta$. It resulted in significant increases in left ventricular $\mathrm{dP} / \mathrm{dtmax}$ and SOD, in addition to apparent improvement in cardiac histopathology with a significant decrease in percentage area of collagen deposition compared to perindopril alone. Conclusion: Co-administration of melatonin to perindopril in hypertensive rats who received doxorubicin alleviated doxorubicin cardiac toxicity more than using perindopril alone. These effects could be explained by the reported antihypertensive, anti-inflammatory, anti-oxidant, and antifibrotic effects of melatonin.
\end{abstract}

Key words Melatonin; Perindopril; Doxorubicin; L-NAME; Cardiotoxicity

\section{Introduction}

TTypertension has been identified as the most common comorbid condition reported in cancer $\perp$ registries (Jain and Townsend, 2007). For example, $73 \%$ of the patients with diffuse large B-cell lymphoma had hypertension (Hershman et al., 2008). Doxorubicin (DOX) is an anthracycline antibiotic with high anti-neoplastic activity to breast cancer, aggressive lymphomas, childhood solid tumors and soft tissue sarcomas (Volkova and Russell, 2011). Anthracycline chemotherapy is still associated with a substantial risk of clinically silent or overt cardiotoxicity, even several years after the end of chemotherapy. African-American ethnicity, very young or very old age, diabetes, hypertension, very high or very low body weight, or severe co-morbidities showed increased risk for development of cardiotoxicity. So patients with $\geq 1$ of the previously mentioned risk factors should be offered preventive means to reduce the risk of cardiotoxicity (Lotrionte et al., 2013). Patients with hypertension showed a higher probability of developing DOX-induced heart failure (Hequet et al., 2004; Pinder et al., 2007; Szmit et al., 2014). Indeed, studies have also shown hypertension to be a strong predictor for DOX-related congestive heart failure (Swain et al., 2003) with "an acceptable prognostic role" (Lotrionte et al., 2013). In turn, this caused hypertensive patients to have more 
delays in subsequent treatment, more reductions in DOX doses, and early discontinuation of chemotherapy (Szmit et al., 2014). Accordingly, an aggressive effort to reduce hypertension in patients who are about to receive DOX should be considered (Hershman et al., 2008).

The pathophysiology of cardiomyocyte injuries by hypertension and DOX may be related to oxidative stress, fibrotic and inflammatory processes (Kuriakose et al., 2016). DOX is known to produce hydroxyl radicals, hydrogen peroxide and superoxide anions (Rajagopalan et al., 1988; Lee et al., 1991). These reactive oxygen species (ROS) may modify cardiac metabolism and mechanics leads to cellular dysfunction and worsening of cardiac functions (Munzel et al., 2015). ROS induced injury of membrane lipids is considered to be the most important factor responsible for the development of DOX-induced cardiotoxicity (Sarvazyan et al., 1995). MDA which is a major lipid peroxidation end product may contribute to increased generation of free radicals and/or decreased activities of antioxidant defense system like super oxide dismutase (SOD). SOD scavenges superoxide radical by catalyzing its conversion into hydrogen peroxide and molecular oxygen (Zhou et al., 2006; Jia et al., 2009). The developed oxidative stress results in myocardial necrosis and damage of the cardiac constituents (Rajadurai and Prince, 2006). Subsequently, this myocardial damage leads to leakage of several biochemical markers in the plasma or serum like creatine kinase-MB (CK-MB) (Patel et al., 2010).

The exact mechanisms on how hypertension affects the heart stress remain largely unexplored. Increased systemic vascular resistance stimulates the heart to augment its contractility in order to accommodate a higher afterload. The left ventricle undergoes concentric hypertrophy to compensate such higher mechanical demands. With cardiac remodeling, an increase in left ventricular mass and wall thickening would eventually lead to gradual decrease in contractility and filling properties, largely due to increased tissue fibrosis. Studies have implicated the role of angiotensin II, transforming growth factor- $\beta 1$ (TGF- $\beta 1$ ), and tumor necrosis factor $\alpha$ (TNF- $\alpha$ ) as the mediators of myocyte damage during the transition from compensated to decompensated heart failure (Testa et al., 1996, Hunter and Chien, 1999). Administration of angiotensinconverting enzyme inhibitor showed significant efficacy and safety in reducing cardiotoxicity in high-risk cancer patients undergoing anthracycline treatment (Cardinale et al., 2006). These drugs primarily reduce blood pressure, which, in turn, decreases the compensatory burden faced by the heart.

The pineal hormone melatonin (MT) is known to have both direct and indirect antioxidant actions as it attenuates lipid peroxidation and DNA degradation due to the direct scavenging of ROS and activation of DNA reparation enzymes. In other words, MT indirectly stimulates antioxidant properties. It has antiinflammatory action as it blocks transcriptional factors that induce pro-inflammatory cytokines (De Talamoni et al., 2014).

The present study was designed to elucidate the possible beneficial effects of MT co-administration to perindopril regarding cardiac functions, myocardial damage, oxidative stress, inflammation and fibrosis, together with identification of histopathological changes resulted from doxorubicin administration in (L-NAME) hypertensive rats.

\section{Materials and methods Chemicals}

Perindopril Arginine was purchased from Servier Industries Ltd. (France). MT (N-acetyl-5methoxytryptamine) supplied as white pills were purchased from Twinlab (USA) and N-Omega-Nitro-LArginine Methyl Ester Hydrochloride (L-NAME) purchased from Glentham, Life sciences, (UK). DOX hydrochloride (Adricin) was purchased from EIMC United Pharmaceuticals (Egypt). Urethane was purchased from Sigma Aldrich Chemicals (Germany). All were dissolved and diluted in distilled water.

\section{Animals}

Thirty-six male albino rats (weighting 200-250 g) were purchased from the National Research Institute (Cairo, Egypt) and housed in an animal room with $12 \mathrm{~h}$ light/dark cycle with free access to food and water. They were fed on rat chow. All animal procedures were carried out in accordance with the National Institute of Health guide for the care and use of laboratory animals (NIH Publication No. 85-23, revised 1996) and were approved by the Institutional Animal Ethics Committee for Ain Shams University, Faculty of Medicine (FWA 00001809).

Methods

Induction of hypertension:

Hypertension was induced with daily oral administration of L-NAME (40 mg/kg/day) for 8 weeks by gastric gavage (Raja, 2010). At the end of $5^{\text {th }}$ week of the experiment, the systolic blood pressure (SBP) was measured to ensure hypertension development and enrolment in the study.

\section{Animal groups and drugs administration:}

Rats were divided randomly into two main groups: Naive group ( $\mathrm{n}=6)$ and L-NAME (hypertensive) group in which L-NAME was administered to the rats orally for 8 weeks for induction of hypertension. The latter group was further subdivided into 5 subgroups (6 animals each): untreated, DOX that received DOX (2.5 $\mathrm{mg} / \mathrm{kg} /$ twice per week) by intraperitoneal injection; DOX/Perindopril (PD) that received perindopril (in its antihypertensive dose $5 \mathrm{mg} / \mathrm{kg} /$ day; Louise et al., 2005) by daily oral gavage; DOX/MT that received MT (10 mg /kg; Simko et al., 2014) by daily oral gavage; and DOX/PD/MT that received perindopril $(5 \mathrm{mg} / \mathrm{kg} /$ day $)$ and MT (10 $\mathrm{mg} / \mathrm{kg}$ ) by daily oral gavage. All drugs were administered daily for 3 weeks starting from the $6^{\text {th }}$ to $8^{\text {th }}$ week of the experiment. When MT or PD was given in combination with DOX, they were administered $3 \mathrm{~h}$ before DOX injection. MT dose was selected from 
previous works, such that it lowered blood pressure and protected the cardiovascular system against deleterious effect of hemodynamic overload (Mukherjee et al., 2012) with no sedative effects (Simko et al., 2014).

\section{Outcome measures:}

\section{Measurement of systolic blood pressure (SBP):}

Non-invasive SBP measurement was done using the tail-cuff technique of Power Lab (NIBP, AD Instruments, and Australia). Measurement was carried out on conscious rats at three occasions of the experiment (Baseline, end of $5^{\text {th }}$ weeks and end of $8^{\text {th }}$ week).

Measurement of left ventricular end diastolic pressure (LVEDP) and left ventricular $\mathrm{dP} / \mathrm{dt}_{\max }$ :

At the end of the study, each rat was anesthetized by urethane $(1.2 \mathrm{~g} / \mathrm{kg})$ i.p. Then the animals were dissected according to a previous study (Wu et al., 2011) as follows. They were fixed and intubated, and an incision was done over the xiphoid process. The chest wall and diaphragm were cut through to expose the apex of the heart. A stab wound was made near the apex of the heart using a 25-30 gauge needle. After the removal of the needle, the catheter tip (Millar Mikro-Tip ${ }^{\circledR}$ pressure catheter) was inserted retrograde into the left ventricle. After stabilization of the signal for $10 \mathrm{~min}$, the LVEDP and $\mathrm{LV} \mathrm{dP} / \mathrm{dt}_{\max }$ were recorded. $\mathrm{LV} \mathrm{dP} / \mathrm{dt}_{\max }$ (the maximal ascending rate of left ventricular pressure during left ventricular isovolemic relaxation) which is considered as an index for cardiac contractility. The catheter was connected to the cable of the pressure module of the Power Lab instrument.

\section{Samples preparation}

After hemodynamic measurements, blood samples were collected in test tubes from the aorta of each rat. Samples were subsequently centrifuged at 5000 r.p.m for $15 \mathrm{~min}$, and the serum was stored at $-80{ }^{\circ} \mathrm{C}$ until assayed. Heart homogenate was prepared according to the method described by a previous study (Noori et al., 2012). Briefly, after cutting the samples and checking for weight, the phosphate buffer saline was added in the ratio of $4 \mathrm{~g}$ tissue for $16 \mathrm{~mL}$ of phosphate buffer $(\mathrm{pH}=7.5)$. The homogenates were centrifuged at 2,000 r.p.m for 20 min at $4{ }^{\circ} \mathrm{C}$, and the supernatant was frozen at $-80{ }^{\circ} \mathrm{C}$ until analysis.

Creatine Kinase-MB (CK-MB) isoenzyme level in rat serum: CK-MB isoenzyme was determined by using a double-antibody sandwich enzyme-linked immunosorbent corresponding ELISA kit purchased from Shanghai Crystal Day Biotech Co., Ltd. CK-MB isoenzyme added to monoclonal antibody enzyme well which was pre-coated with rat CK-MB isoenzyme monoclonal antibody.

Malonyldehyde (MDA) level in heart homogenate: The MDA level was determined using diagnostic kits (Jiangchen, Nanjing, China) with a UVvisible spectrophotometer (Shimadzu, Kyoto, Japan) according to the manufacturer's instructions. Simply, it involved the reaction of one molecule of the malondialdehyde and two molecules of thiobarbituric acid to form a red MDA-thiobarbituric acid complex that can be quantified using the spectrophotometer at $535 \mathrm{~nm}$ wave length.

Superoxide dismutase (SOD) level in heart homogenate: The SOD level was determined using a corresponding ELISA kit purchased from Cell Biolabs, Inc. (USA). The absorbance was read at $490 \mathrm{~nm}$ on a microplate reader.

Tumor necrosis factor-alpha (TNF- $\alpha$ ) level in heart homogenate: The TNF- $\alpha$ was determined using rat TNF- $\alpha$ ELISA kit purchased from Quantikine ${ }^{\circledR}$ (USA). A monoclonal antibody specific for rat TNF- $\alpha$ was precoated onto a microplate. Standards control and samples were pipetted into the wells, and any rat TNF- $\alpha$ present was bound by the immobilized antibody. After washing away any unbound substances, an enzyme-linked polyclonal antibody specific for rat TNF- $\alpha$ was added to the wells. The sample values are then read off the standard curve, and the absorbance was measured at $450 \mathrm{~nm}$.

Transforming growth factor-beta (TGF- $\beta$ ) level in heart homogenate: The TGF- $\beta$ level was determined by using a corresponding ELISA kit purchased from Sigma-Aldrich Co. The heart samples were centrifuged for 20 minutes at $1000 \times$ g. The microtiter plate provided in this kit was pre-coated with an antibody specific to TGF- $\beta$. The color change is measured spectrophotometrically at a wavelength of 450 $\mathrm{nm} \pm 10 \mathrm{~nm}$.

Histopathological study of heart samples:

Heart specimens were collected at the end of the experiments. The wall of each heart was cut longitudinally, and the left ventricle was cut into small specimens fixed in $10 \%$ formal-saline for one week. This was followed by dehydration, clearing and embedding in paraffin. Serial sections were cut at a thickness of $5 \mu \mathrm{m}$ and subjected to hematoxylin \& eosin staining and Masson's triple stain for detecting collagen fibers that appeared green in color.

Morphometric studies of histopathological sections:

Six different stained sections of the wall of the heart from six rats were examined in each group. Five high power fields/sections were chosen to measure the percentage area of collagen fibers in the myocardium. The sections were examined using an image analyzer Leica Q win V.3 program installed on a computer in the Histology Department Faculty of Medicine Ain Shams University. The computer was connected to Leica DM2500 microscope (Wetzlar, Germany).

\section{Statistical Analysis:}

Statistical analysis was carried out using Graph pad prism software program, version 5.0. (2007) (Inc., CA, USA). All values in the results were expressed as means \pm SD. Statistical differences among groups were determined using one-way analysis of variance (ANOVA) followed by Tukey's multiple comparison test. But for blood pressure, two-way ANOVA test was used with Bonferroni's post-hoc test. $\mathrm{P}$ values $<0.05$ were considered statistically significant. 


\section{Results}

\section{Effect on systolic blood pressure (SBP):}

Table (1) shows that there were insignificant differences in baseline (day 0) SBP recordings among all rat groups. After 5 weeks of L-NAME administration, there was a significant increase in SBP in all named groups before any drug administration when compared to their baseline (day 0) recording. L-NAME untreated rats exhibited insignificant increase in the $8^{\text {th }}$ week compared to the $5^{\text {th }}$ week. DOX administration for 3 weeks resulted in a significant decrease in SBP to $5^{\text {th }}$ week. Rats who received $\mathrm{PD}, \mathrm{MT}$ and $\mathrm{PD} / \mathrm{MT}$ in concomitant with $\mathrm{DOX}$ showed a significant decrease in their SBP by when compared to their $5^{\text {th }}$ week recordings. In addition, there was insignificant difference in SBP in DOX/PD/MT treated rats in comparison to DOX/PD treated rats.

Effect on LVEDP and Left Ventricular dP/dtmax :

As depicted in figure (1 A \& B), L-NAMEuntreated and DOX administered rats showed a significant increase in LVEDP and decrease in LV $\mathrm{dP} / \mathrm{dt}_{\max }$ in comparison to naive group by $25.5 \%$, $57.98 \%$ and $52.3 \%, 84.7 \%$, respectively. The hypertensive rats who received DOX exhibited a significant increase in LVEDP by $21.5 \%$ and decrease in $\mathrm{LV} \mathrm{dP} / \mathrm{dt}_{\max }$ by $36.5 \%$ when compared with L-NAME-untreated rats. There was a significant decrease in LVEDP and a significant increase in $\mathrm{LV} \mathrm{dP} / \mathrm{dt}_{\max }$ in DOX/PD and DOX/PD/MTtreated rats by $17.7 \%, 233.1 \%$ and $32.3 \%$, 382.9\%, respectively, in comparison to DOX rats. Meanwhile, DOX/MT insignificantly decreased LVEDP by $15.6 \%$ and significantly increased $\mathrm{LV} \mathrm{dP} / \mathrm{dt}_{\max }$ by $354.9 \%$. Furthermore, there was a significant decrease in LVEDP and an increase in $\mathrm{LV} \mathrm{dP} / \mathrm{dt}_{\max }$ by $17.6 \%$ and $44.99 \%$, respectively, in DOX/PD/MT-treated rats when compared to DOX/PD-treated rats.

\section{Effect on CK-MB isoenzyme:}

As shown in figure (1-C), hypertensive untreated rats and DOX rats exhibited a significant increase in CK-MB isoenzyme by $161.5 \%$ and $235.9 \%$, respectively, when compared to naive rats. The DOX subgroup showed increased CK-MB isoenzyme level by 28.4\% over untreated subgroup. Administration of PD and MT either alone or in combination to DOX significantly decreased CK-MB isoenzyme by $65 \%$, $38.5 \%$, and $36.5 \%$, respectively, in comparison to DOX rats. There was an insignificant difference in CK-MB isoenzyme in $\mathrm{DOX} / \mathrm{PD} / \mathrm{MT}$ treated rats in comparison to $\mathrm{DOX} / \mathrm{PD}$ rats.

\section{Effect on MDA and SOD:}

As shown in figure (2 A \& B), hypertensive untreated and DOX rats exhibited a significant increase in MDA and decrease in SOD by $169.6 \%$, 55.8\% and 248\%, $71.9 \%$, respectively, as compared to naive group. A notable significant increase in MDA by $29.1 \%$ and a decrease in SOD by $57.4 \%$ were observed in DOX subgroup when compared to L-NAME untreated rats. Administration of PD and MT either alone or in combination to DOX significantly decreased MDA and increased SOD by
$51.4 \%, 48.9 \%, 65 \%$ and $148.5 \%, 104.5 \%, 208.4 \%$, respectively, in comparison to DOX rats. It is worthy to mention that $\mathrm{DOX} / \mathrm{PD} / \mathrm{MT}$ rats showed a significant decrease in MDA by $27.97 \%$ and an increase in SOD by $24.1 \%$ when compared to DOX/PD rats.

Effect on TNF- $\alpha$ :

Figure 2-C shows that hypertensive untreated and DOX rats exhibited a significant increase in TNF- $\alpha$ by $123.5 \%$ and $203.9 \%$, respectively, as compared to naive group, with significant increase in DOX by $35.96 \%$ compared to untreated subgroup. Administration of PD and MT either alone or in combination to DOX significantly decreased TNF- $\alpha$ by $46.97 \%, 46.77 \%, 61.1 \%$, respectively, in comparison to DOX subgroup. Furthermore, there was a significant decrease in TNF- $\alpha$ in DOX/PD/MT subgroup by $26.6 \%$ in comparison to PD subgroup.

\section{Effect on TGF- $\beta$ :}

As shown in figure 2-D, untreated hypertensive rats and DOX rats exhibited a significant increase in TGF- $\beta$ by $491 \%$ and $666.2 \%$, respectively, as compared to the naive group with a significant increase in DOX by 29.7\%. Administration of PD and MT either alone or in combination to DOX significantly decreased TGF $\beta$ by $63.2 \%, 65.3 \%$, 81.1\%, respectively, in comparison to DOX rats. There was a significant decrease in TGF- $\beta$ in $\mathrm{DOX} / \mathrm{PD} / \mathrm{MT}$-treated rats by $48.5 \%$ in comparison to DOX/PD subgroup.

Histopathological changes in heart tissues:

I. Hematoxyline and Eosin stain:

Examination of stained sections by light microscopy of naive group revealed that the myocardium was formed of branching and anastomosing acidophilic cardiac muscle fibers with large, oval and vesicular nuclei. Nuclei of connective tissue cells in between the cardiac muscle fibers were observed to be flat and darkly stained (figure 3-A). The stained sections of L-NAME untreated and DOX subgroups showed extravasated blood cells between cardiac muscle fibers. Some fibers showed pyknotic nuclei while others were disrupted, fragmented and widely separated (figures 3-B \& C). The stained sections of DOX/PD subgroup revealed some areas with congested interstitial blood capillaries between muscle fibers (figure 3-D), while those of DOX/MT subgroup showed some cardiac muscle fibers to be disorganized with widening of interstitial spaces (figure $3-\mathrm{E})$. The stained sections of $\mathrm{DOX} / \mathrm{PD} / \mathrm{MT}$ subgroup showed the cardiac muscle fibers to be slightly disorganized with mild spacing and extravasated blood cells (figure 3-F).

\section{Masson's trichrome stain:}

Sections of naive normal rats showed few collagenous fibers surrounding cardiac muscle fiber (figure 4-A). The stained sections of untreated and DOX subgroups showed a marked increase in the amount of collagen fibers between disorganized, fragmented muscle fibers (figure 4-B \& C) while the sections of DOX/PD subgroup showed a moderate amount of collagen fibers around blood capillaries and between cardiac muscle 
fibers (figure 4-D). Moreover, stained sections from DOX/MT subgroup showed moderate amount of collagen fibers between disorganized muscle fibers (figure 4-E) while that of DOX/PD/MT subgroup showed mild amount of collagen fibers between regularly arranged muscle fibers (figure 4-F).

III. Morphometric analysis:

Notably, the percentage areas of collagen fibers were significantly increased in hypertensive untreated and DOX animals by $602.5 \%$ and $772 \%$, respectively, compared to naive rats with a significant increase by $24.23 \%$ in DOX animals compared to untreated subgroup. Meanwhile, the administration of PD and MT either alone or in combination to DOX significantly decreased the percentages area of collagen fibers by $54.02 \%, 51.62 \%, 82.96 \%$, respectively, in comparison to DOX rats. Furthermore, there was a significant decrease in percentage areas of collagen fibers in $\mathrm{DOX} / \mathrm{PD} / \mathrm{MT}$ by $62.99 \%$ in comparison to DOX/PD (Table 2).

Table (1): Two-ways ANOVA followed by Bonferroni's post-hoc test for comparison the corresponding groups. One way ANOVA followed by Tukey's multiple comparison test for comparison between different groups regarding effect on systolic blood pressure (SBP).

\begin{tabular}{|c|c|c|c|c|c|c|}
\hline Rat groups & Naive & \multicolumn{4}{|c|}{ L-NAME } \\
\cline { 3 - 6 } & & Untreated & DOX & DOX/PD & DOX/MT & DOX/PD/MT \\
\hline $\begin{array}{c}\text { SBP (mmhg) } \\
\text { day 0 }\end{array}$ & $119 \pm 1.97$ & $120 \pm 3.52$ & $118 \pm 3.08$ & $123 \pm 3.08$ & $123 \pm 5.01$ & $119 \pm 6.91$ \\
\hline $\begin{array}{c}\text { SBP (mmhg) } \\
\mathbf{5}^{\text {th }} \text { week }\end{array}$ & $121 \pm 3.54$ & $161 \pm 10.2^{\mathrm{a}}$ & $162 \pm 14.8^{\mathrm{a}}$ & $162 \pm 9.36^{\mathrm{a}}$ & $157 \pm 7.48^{\mathrm{a}}$ & $154 \pm 9.81^{\mathrm{a}}$ \\
\hline $\begin{array}{c}\text { SBP (mmh) } \\
\mathbf{8}^{\text {th }} \text { week }\end{array}$ & $120 \pm 2.79$ & $163 \pm 9.70^{\mathrm{c}}$ & $111 \pm 2.61^{\mathrm{b}}$ & $105 \pm 2.86^{\mathrm{b}}$ & $125 \pm 5.29^{\mathrm{b}}$ & $106 \pm 3.73^{\mathrm{b}}$ \\
\hline
\end{tabular}

$n=6$ per group. ${ }^{a} \mathrm{P}<0.05$ compared to corresponding baseline $S B P,{ }^{b} P<0.05$ compared to corresponding $5^{\text {th }}$ week $S B P$. ${ }^{c} P$ $<0.05$ compared to naive group. $S B P=$ Systolic blood pressure, $P D=$ perindopril, $M T=$ melatonin, $D O X=d o x o r u b i c i n$.

Table 2: One-way ANOVA followed by Tukey's multiple comparison test to compare the effect on cardiac percentage area of collagen fibers.

\begin{tabular}{|c|c|c|c|c|c|c|}
\hline \multirow{2}{*}{$\begin{array}{c}\text { Rat } \\
\text { Groups }\end{array}$} & Naïve & \multicolumn{3}{|c|}{ L-NAME } \\
\cline { 3 - 6 } & & Untreated & DOX & DOX/PD & DOX/MT & DOX/PD/MT \\
\hline $\begin{array}{c}\text { Percentage area } \\
\text { of collagen } \\
\text { fibers }\end{array}$ & $2.21 \pm 0.91$ & $16.4 \pm 4.35^{\mathrm{a}}$ & $20.9 \pm 4.95^{\mathrm{b}}$ & $9.38 \pm 2.51^{\mathrm{c}}$ & $9.93 \pm 2.70^{\mathrm{c}}$ & $3.54 \pm 1.14^{\mathrm{c}, \mathrm{d}}$ \\
\end{tabular}

$n=6$ per group. ${ }^{a} \mathrm{P}<0.05$ compared to naive group, ${ }^{b} \mathrm{P}<0.05$ compared to untreated subgroup, ${ }^{c} \mathrm{P}<0.05$ compared to DOX subgroup, ${ }^{d} P<0.05$ compared to $P D$ subgroup. $M T=$ melatonin, $P D=$ perindopril, $D O X=$ doxorubicin, values are mean \pm $S D$ (standard deviation). 


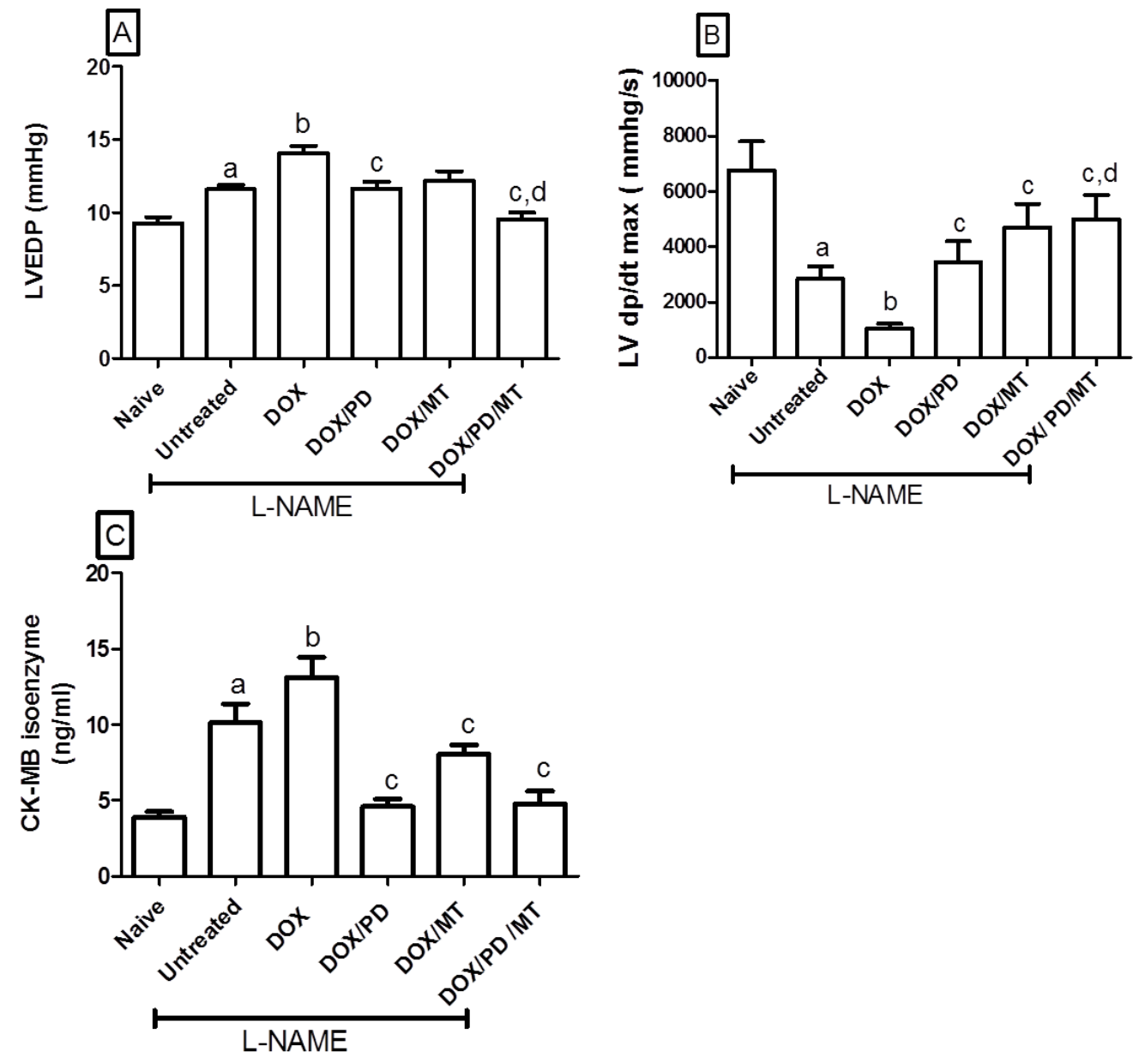

Figure-1 (A-D): Effect on (A) LVEDP, (B) LV dp/dtmax, (C) heart rate and (D) cardiac CK-MB isoenzyme in hypertensive rats. Values are mean $\pm \mathrm{SD} ; n=6$ per group, One-way ANOVA followed by Tukey's multiple comparison test. ${ }^{\text {a }} \mathbf{P}<\mathbf{0 . 0 5}$ compared to naïve group. ${ }^{b} \mathbf{P}<\mathbf{0 . 0 5}$ compared to $\mathrm{L}-\mathrm{NAME}$ untreated subgroup. ${ }^{\mathrm{c}} \mathbf{P}<\mathbf{0 . 0 5}$ compared to DOX subgroup. ${ }^{\mathrm{d}} \mathbf{P}<0.05$ compared to $P D$ subgroup. $L$ VEDP $=$ left ventricular end diastolic pressure, LV dp/dt $\mathrm{dmax}_{\max }$ left ventricular delta pressure/delta time maximum MT = melatonin, $\mathrm{PD}=$ perindopril, $\mathrm{DOX}=$ doxorubicin. 

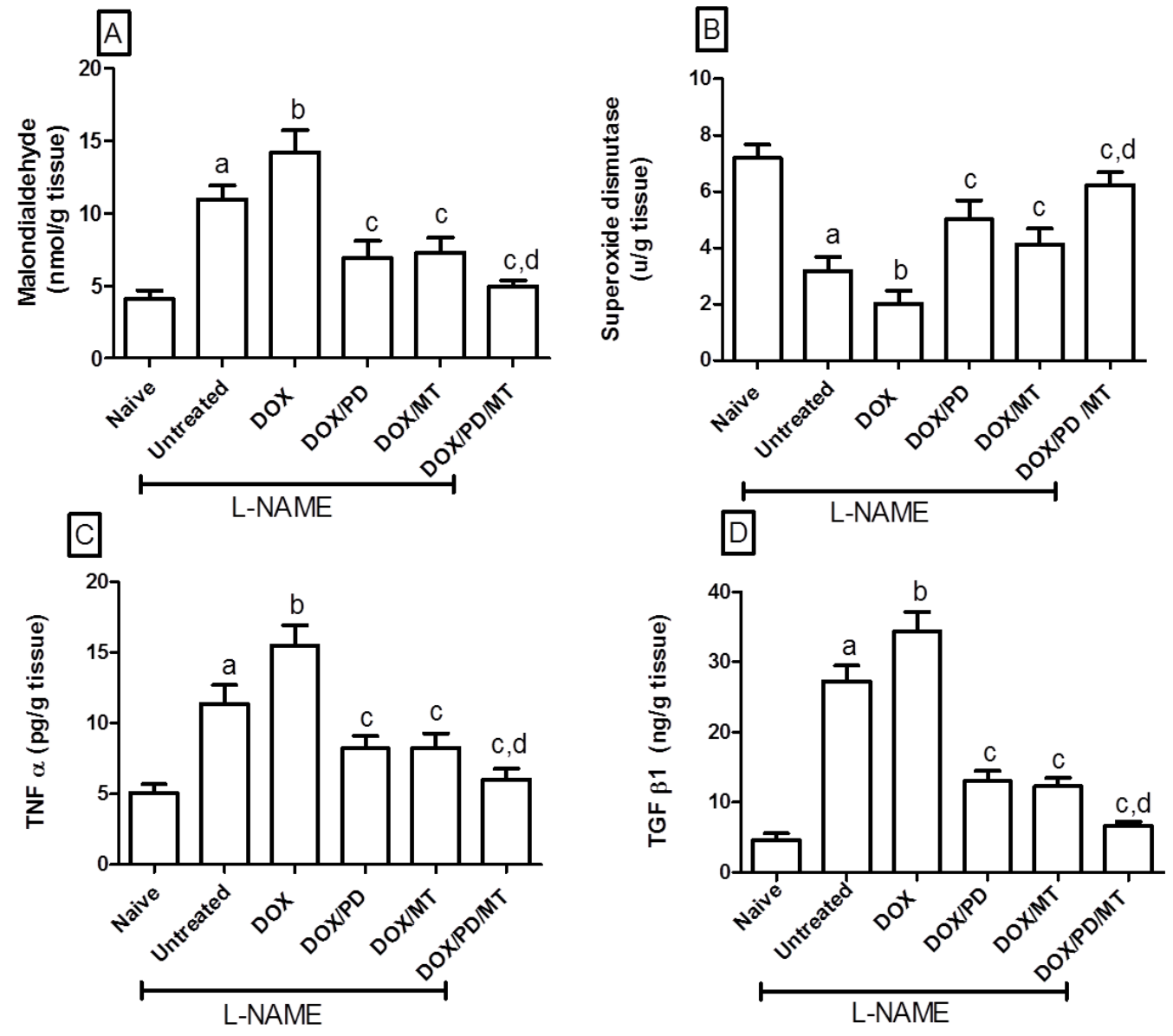

Figure-2 (A-D): Effect on cardiac (A) Malondialdehyde, (B) superoxide dismutase, (C) cardiac TNF- $\alpha$ and (D) cardiac TGF- $\beta$ in hypertensive rats. Values are mean $\pm S D ; n=6$ per group, One-way ANOVA followed by Tukey's multiple comparison test. ${ }^{a} \mathbf{P}<\mathbf{0 . 0 5}$ compared to naive group. ${ }^{b} \mathbf{P}<\mathbf{0 . 0 5}$ compared to L-NAME untreated subgroup. ${ }^{c} \mathbf{P}<0.05$ compared to DOX subgroup. ${ }^{\mathrm{d}} \mathbf{P}<0.05$ compared to $\mathrm{PD}$ subgroup. $\mathrm{MT}=$ melatonin, $\mathrm{PD}=$ perindopril, $\mathrm{DOX}=$ doxorubicin. 

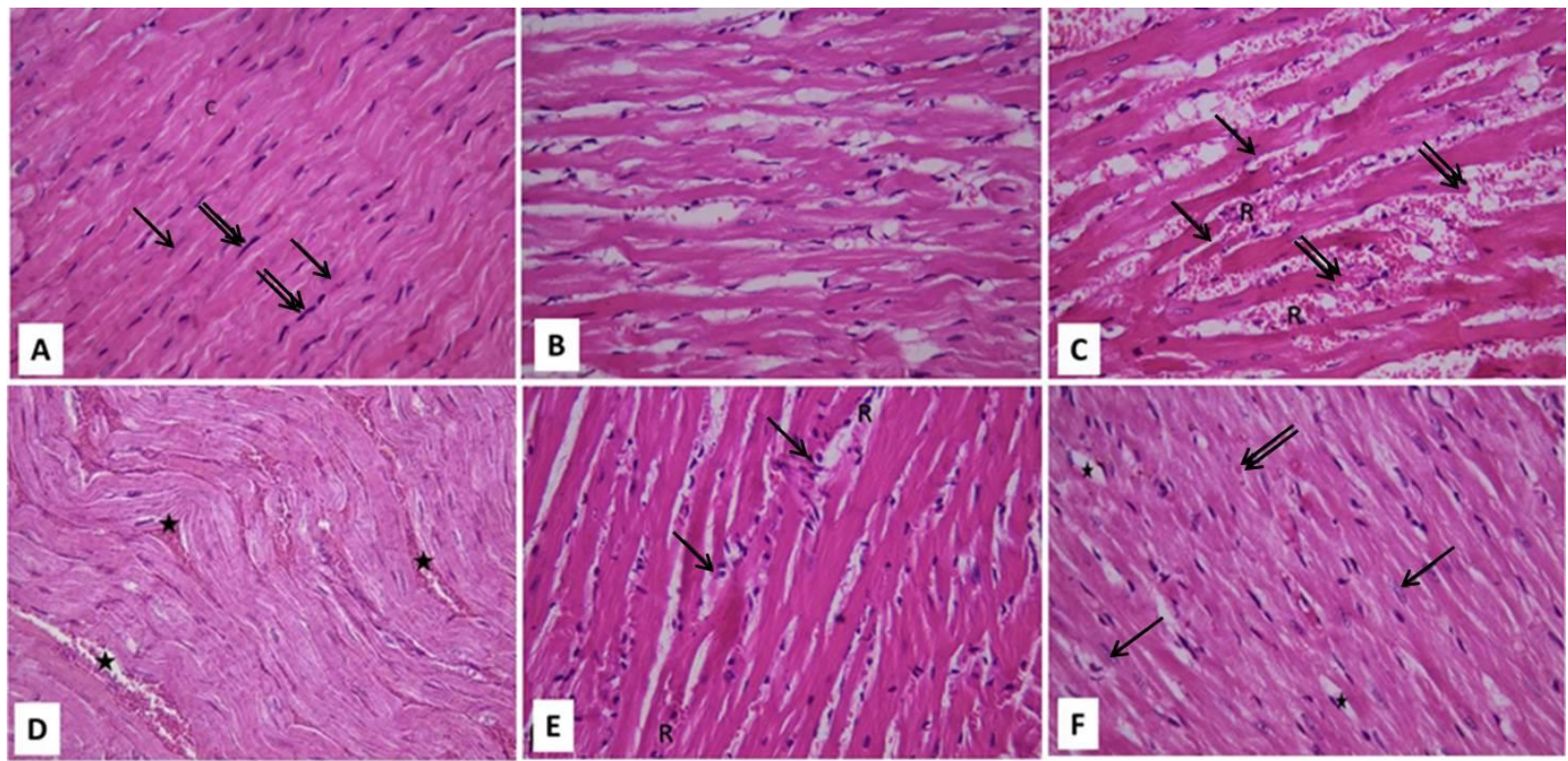

Figure (3 A-F): Photomicrographs of myocardium of rats from different groups (H\&E X540): (A) Naive group, showing acidophilic cardiac muscle fibers $(C)$ with large vesicular $(\uparrow)$ nuclei. Note darkly stained nuclei of connective tissue cells between the muscle fibers ( $\uparrow$ ). (B) L-NAME untreated subgroup, (C) (B) DOX subgroup showing extravasated blood cells (R) between fibers. Notice some fibers with pyknotic nuclei $(\uparrow)$ while others disrupted, fragmented and widely separated ( $\uparrow$ ). (D) DOX/PD subgroup, showing some areas with congested interstitial blood capillaries $(*)$ between muscle fibers. (E) DOX/MT subgroup, showing some cardiac muscle fibers disorganized with widening of interstitial spaces $(\uparrow)$. Note extravasated blood cells $(R)$ between fibers. (F) DOX/PD/MT subgroup, showing nearly similar to the control group. The cardiac muscle fibers are slightly disorganized with mild spacing $(*)$ having vesicular nuclei $(\uparrow)$. Notice mildly extravasated blood cells $(\uparrow \uparrow)$. 

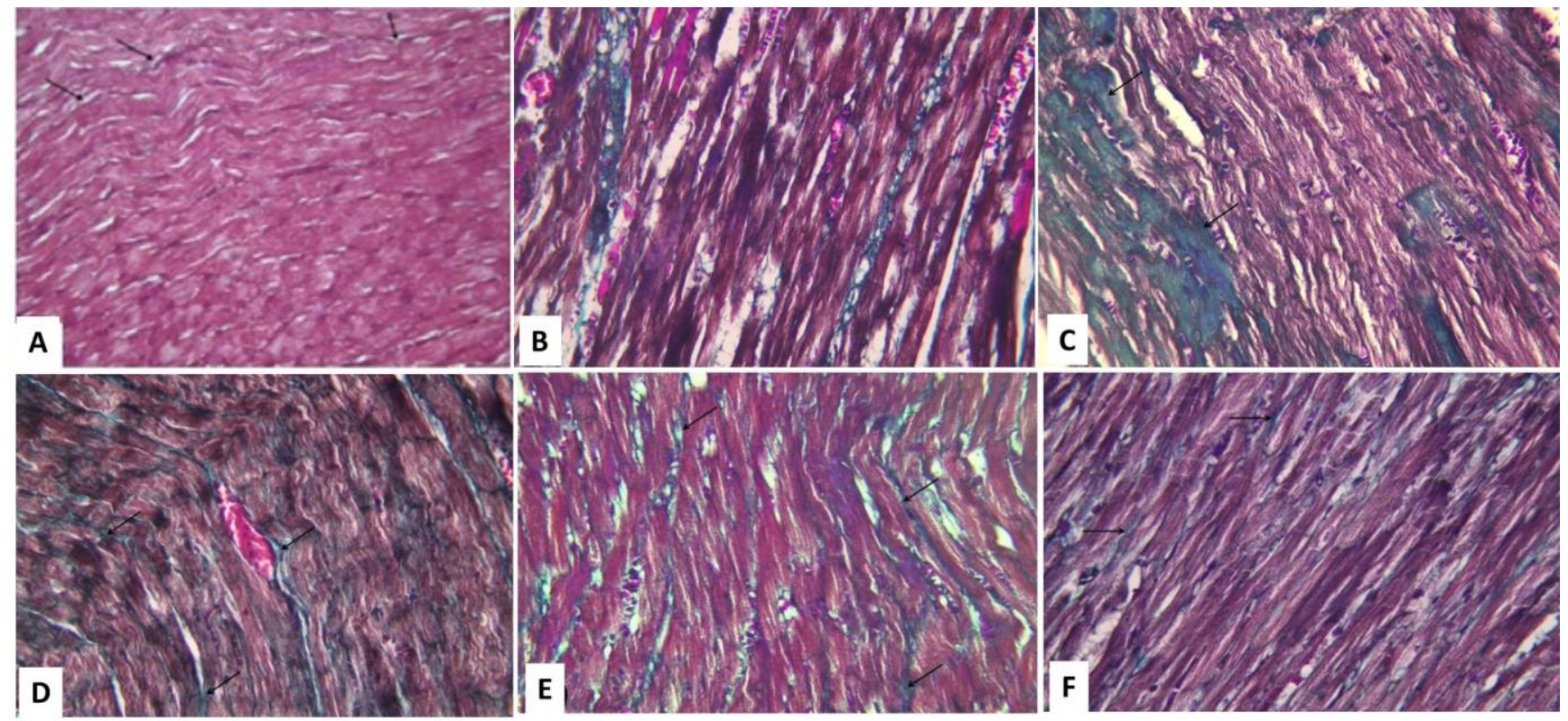

Figure (4 A-F): Photomicrographs of myocardium of rats from different groups (Masson X540): (A) Naive group, showing mild amount of collagen fibers (green) $(\uparrow)$ between cardiac muscle fibers. (B) L-NAME untreated subgroup, showing moderate increase in the amount of collagen fibers. (C) DOX subgroup showing marked increase in the amount of collagen fibers $(\uparrow)$ between disorganized, fragmented muscle fibers (D) DOX/PD subgroup, showing moderate amount of collagen fibers $(\uparrow)$ around blood capillaries and between cardiac muscle fibers. (E) DOX/MT subgroup, showing moderate amount of collagen fibers $(\uparrow)$ between disorganized muscle fibers. (F) DOX/PD/MT subgroup, showing few amount of collagen fibers between $(\uparrow)$ between regularly arranged cardiac muscle fibers.

\section{Discussion}

In the present study, DOX administration to hypertensive rats showed a decrease in SBP, increase in LVEDP and

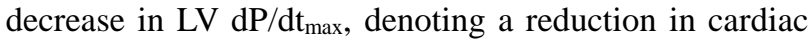
functions especially myocardial contractility. These findings are in accordance with previous studies (Warpe et al., 2015; Gandhi et al., 2013). These changes were associated with development of oxidative stress as evidenced by a decrease in SOD levels, increase in MDA and myocardial damage which was evidenced by a significant increase in serum CK-MB. The heart's unique vulnerability to oxidative stress has given this aspect of DOX-induced cardiomyopathy an overwhelming prominence in the literature (Octavia et al., 2012). The cardiac oxidative stress promotes the development of cardiac fibrosis by upregulating TGF- $\beta$ expression, which subsequently enhances cardiac collagen synthesis and suppresses collagen degradation in hypertensive rats. This is evidenced by increased cardiac percentage area of collagen fibers deposition in the present study (Zhao et al., 2008; Al-Shabanah et al., 2012), along with an increased level of cardiac TNF- $\alpha$ (Pecoraro et al., 2016). All of these findings lead to significant cardiac pathology and increased mortality (Octavia et al., 2012).

Agents that can prevent or attenuate fibrotic reactions may prove to be important additions to the therapeutic aims for managing patients at risk with the goal of early intervention before fibrosis (Feldman et al., 2016).
In accordance with Mukherjee and his colleagues (2012), MT administration produced significant antihypertensive effect with increased cardiac contractility. Co-administration of MT to PD in rats who received DOX produced a significant decrease in SBP and better control of cardiac hemodynamics in comparison to PD alone. The antihypertensive effect of MT could be explained in part by the activation of MT receptors on endothelial cells. This could also trigger the formation of nitric oxide (NO), whose vasodilatory potential could overwhelm the MTdependent contraction of smooth muscle cells (Paulis and Simko, 2007). As a result, the antihypertensive effect of MT is less pronounced in L-NAME-induced NO-deficient hypertension compared with other studies on spontaneously hypertensive rats (Pechanova et al., 2007; Simko et al., 2009). This could be related to the L-NAMEinduced blockade of endothelial nitric oxide synthase (eNOS) activity that might have disabled MT from improving the NO pathway. Thus, some data support the idea that augmentation of NO-signaling plays an important role in the antihypertensive action of MT (Paulis and Simko, 2007). However, the antihypertensive effect of MT is mediated by other mechanisms including a direct hypothalamic effect, a lowering of catecholamine levels, and most importantly, its antioxidant properties, which contribute to better vascular functions and blood pressure regulation (Tengattini et al., 2008; Pechanova et al., 2014). Besides, MT could apparently potentiate acetylcholine effects by central MT receptor stimulation (Weekley, 
1995). Furthermore, chronic administration of MT decreased the blood pressure, inhibited the sympathetic activity, restored cardiac $\beta$-adrenoceptor function, and improved baroreflex (Girouard et al., 2004). In healthy young men, MT reduced the SBP along with norepinephrine levels and reduced blood pressure and pulse wave velocity in association with the attenuation of sympathetic tone (Yildiz et al., 2006).

MT is a powerful antioxidant which can limit damage in cardiovascular disease (Yang et al., 2014), and a lot of studies have demonstrated that MT influences antioxidant enzyme activities after the administration of free radical generating substances (Rodriguez et al., 2004). It has direct and indirect antioxidant actions as it attenuates lipid peroxidation with a decrease in MDA level and DNA degradation due to direct scavenging of both ROS and activation of DNA reparation enzymes. Indirectly, MT has antioxidant actions through stimulation of enzyme activation like SOD (Şehirli et al., 2013; De Talamoni et al., 2014). In a model of pulmonary hypertension (Maarman et al., 2015), it was found that plasma SOD activity was increased by chronic daily administration of MT either as a preventive or a curative treatment.

In agreement with the current study, a previous study (Patel et al., 2010) reported that pretreatment of MT resulted in reduced activity of CK-MB enzyme in serum in a model of isoproterenol-induced heart failure. Thus, MT could maintain membrane integrity, thereby, restricting the leakage of these enzymes.

Co-administration of MT and PD to DOX produced better control of inflammatory and fibrotic reactions than PD alone by significant decreases in TNF- $\alpha$, TGF- $\beta$ and percentage area of cardiac fibrosis. The anti-inflammatory and antifibrotic effects of PD have been reported previously (Madej et al., 2009; Toblli et al., 2005). The anti-inflammatory mechanism of MT could decrease the NF- $\mathrm{KB}$ expression in endothelial cells of spontaneously hypertensive rats (Tamura et al., 2009). It mediated this effect through the regulation of gene transcriptional and translational levels in human vascular smooth muscle cell (Shi et al., 2012). MT significantly attenuated the cardiac fibrosis by lowering the mRNA expression of genes associated with cardiac hypertrophy, especially TGF- $\beta$ in the hypoxic rats (Yeung et al., 2015). The antifibrotic effect of MT was also demonstrated in a model of L-NAME-induced hypertension and in a model of combined continuous light exposure and L-NAME administration (Paulis et al., 2009; Simko et al., 2010). As mentioned before, the antifibrotic effect of MT could be attributed to not only its ability to decrease TGF- $\beta$ but also its powerful antioxidant properties (Al-Shabanah et al., 2012).

\section{Conclusion}

Co-administration of MT and PD in hypertensive rats received DOX alleviated DOX cardiac toxicity more than using PD alone. These effects could be explained by the reported antihypertensive, anti-inflammatory, antioxidant, and anti-fibrotic effects of MT. Accordingly, it would be valuable to test MT in clinical trials for prevention of possible heart damage associated with DOX in hypertensives.

Declarations:

- Competing interests: The authors declare that they have no competing interests.

- Funding: Self-funded research

- Acknowledgements: Not applicable

\section{References}

Al-Shabanah OA, Aleisa AM, Hafez MM, et al. (2012). Desferrioxamine Attenuates Doxorubicin Induced Acute Cardiotoxicity through TFG$\beta /$ Smad Pathway in Rat Model. Oxidative medicine and cellular longevity, 53.

Cardinale D, Colombo A, Sandri MT, et al. (2006). Prevention of high-dose chemotherapy-induced cardiotoxicity in high risk patients by angiotensin-converting enzyme inhibition. Circulation, 114 (23), 2474-2481.

De Talamoni NT, Areco VA, Lopez MEP, et al. (2014). Past, Present, and Future of Melatonin's Clinical Uses. In Melatonin and Melatonergic Drugs in Clinical Practice, 27-42.

Feldman AM, Haller JA and DeKosky ST (2016). Valsartan/Sacubitril for Heart Failure: Reconciling Disparities between Preclinical and Clinical Investigations. JAMA, 315(1), 25-26.

Gandhi H, Patel VB, Mistry N, et al. (2013). Doxorubicin mediated cardiotoxicity in rats: Protective role of felodipine on cardiac indices. Environmental toxicology and pharmacology, 36(3), 787-795.

Girouard H, Denault C, Chulak C, et al. (2004). Treatment by $\mathrm{N}$-acetylcysteine and melatonin increases cardiac baroreflex and improves antioxidant reserve. Am. J.Hypertens; 17, 947-954.

Hequet O, Le QH., Moullet Pauli E, et al., (2004). Subclinical late cardiomyopathy after doxorubicin therapy for lymphoma in adults,"Journal of Clinical Oncology, 22 (10), 1864-1871.

Hershman DL, McBride RB, Eisenberger A, et al. (2008). Doxorubicin, cardiac risk factors, and cardiac toxicity in elderly patients with diffuse B-cell non-Hodgkin's lymphoma, Journal of Clinical Oncology, 26(19), 3159-3165.

Hunter JJ. and Chien KR (1999). "Signaling pathways for cardiac hypertrophy and failure. The New England Journal of Medicine. 341 (17), 12761283.

Jain M and Townsend RR (2007). Chemotherapy agents and hypertension: a focus on angiogenesis blockade. Current Hypertension Reports, 9(4), 320-328.

Jia J, Zhang X, Hu YS, et al. (2009). Evaluation of in vivo antioxidant activities of Ganoderma 
lucidum polysaccharides in STZ-diabetic rats. Food Chemistry, 115(1), 32-36.

Kuriakose RK, Kukreja RC, Xi L, (2016). Potential Therapeutic Strategies for HypertensionExacerbated Cardiotoxicity of Anticancer Drugs. Oxid Med Cell Longev, 2016, 8139861.

Lee V, Randhawa AK, Singal PK (1991). Adriamycininduced myocardial dysfunction in vitro is mediated by free radicals. Am J Physiol., 261: H989-995.

Lotrionte M, Biondi-Zoccai G, Abbate A, et al. (2013). Review and meta-analysis of incidence and clinical predictors of anthracycline cardiotoxicity. American Journal of Cardiology, 112 (12), 1980-1984.

Louise M, Burrell, John Risvanis, et al. (2005). Myocardial infarction increases ACE2 expression in rat and humans: European Heart Journal, 26, 369-375.

Maarman G, Blackhurst D, Thienemann F, et al. (2015). Melatonin as a preventive and curative therapy against pulmonary hypertension. Journal of Pineal Research, 59, 343-353.

Madej A, Buldak L, Basiak M, et al. (2009).The effects of 1 month antihypertensive treatment with perindopril, bisoprolol or both on the ex vivo ability of monocytes to secrete inflammatory cytokines. International journal of clinical pharmacology and therapeutics, 47(11), 686694.

Mukherjee D, Ghosh AK, Bandyopadhyay A, et al. (2012). Melatonin protects against isoproterenol induced alterations in cardiac mitochondrial energy metabolizing enzymes, apoptotic proteins, and assists in complete recovery from myocardial injury in rats. Journal of pineal research, 53(2), 166-179.

Münzel T, Gori T, Keaney JF, et al. (2015). Pathophysiological role of oxidative stress in systolic and diastolic heart failure and its therapeutic implications. European heart journal, 36(38), 2555-2564.

Noori S; Azmat M and Mahboob T (2012). Study on antioxidant effects of cinnamon and garlic extract in liver, kidney and heart tissue of rat. Biosci. Res; 9, 17-22.

Octavia Y, Tocchetti CG, Gabrielson KL, et al. (2012). Doxorubicin-induced cardiomyopathy: from molecular mechanisms to therapeutic strategies. Journal of molecular and cellular cardiology, 52(6), 1213-1225.

Patel V, Upaganlawar A, Zalawadia R, et al. (2010). Cardioprotective effect of melatonin against isoproterenol induced myocardial infarction in rats: a biochemical, electrocardiographic and histoarchitectural evaluation. European journal of pharmacology, 644(1), 160-168.
Paulis L and Simko F (2007). Blood pressure modulation and cardiovascular protection by melatonin: Potential mechanisms behind. Physiol Res, 56, 671-684.

Paulis L, Pechanova O, Zicha J, et al. (2009). Melatonin prevents fibrosis but not hypertrophy development in the left ventricle of NG-nitro-Larginine-methyl ester hypertensive rats. Journal of Hypertension, 27, S11-S16.

Pechanova O, Paulis L and Simko F (2014). Peripheral and central effects of melatonin on blood pressure regulation. International journal of molecular sciences, 15(10), 17920-17937.

Pechanova O, Zicha J, Paulis L, et al. (2007). The effect of $\mathrm{N}$-acetylcysteine and melatonin in adult spontaneously hypertensive rats with established hypertension. Eur. J. Pharmacol, 561, 129-136.

Pecoraro M, Del Pizzo M, Marzocco S, et al. (2016). Inflammatory mediators in a short-time mouse model of doxorubicin-induced cardiotoxicity. Toxicology and applied pharmacology, 293, 4452.

Pinder MC, Duan Z, Goodwin JS, et al. (2007). Congestive heart failure in older women treated with adjuvant anthracycline chemotherapy for breast cancer, Journal of Clinical Oncology, 25 (25). 3808-3815.

Raja, B (2010). Antihypertensive and Antioxidant Potential of Borneol-A Natural Terpene in LNAME-Induced Hypertensive Rats. International Journal of Pharmaceutical \& Biological Archive, 1(3).

Rajadurai, M and Prince and P.S.M (2006). Preventive effect of naringin on lipid peroxides and antioxidants in isoproterenol-induced cardiotoxicity in Wistar rats: biochemical and histopathological evidences. Toxicology, 228, 259-268.

Rajagopalan S, Politi PM, Sinha BK, et al. (1988). Adriamycin-induced free radical formation in the perfused rat heart: implications for cardiotoxicity. Cancer Res, 48 (17), 4766-4769.

Rodriguez C, Mayo JC, Sainz RM, et al. (2004). Regulation of antioxidant enzymes: a significant role for melatonin. Journal of pineal research, 36(1), 1-9.

Sarvazyan NA, Askari A, Huang WH, (1995). Effects of doxorubicin on cardiomyocytes with reduced level of superoxide dismutase. Life Sci., 57: 1003-1010.

Şehirli AÖ, Koyun D, Tetik Ş, et al. (2013). Melatonin protects against ischemic heart failure in rats. Journal of Pineal Research, 55, 138-148.

Shi D, Xiao X, Wang J, et al. (2012). Melatonin suppresses proinflammatory mediators in lipopolysaccharide-stimulated CRL1999 cells via targeting MAPK, NF- $\mathrm{BB}, \mathrm{c} / \mathrm{EBP} \beta$, and p300 
signaling. Journal of pineal research, 53(2), 154165.

Simko F, Pechanova O, Pelouch V, et al. (2009). Effect of melatonin, captopril, spironolactone and simvastatin on blood pressure and left ventricular remodelling in spontaneously hypertensive rats. Journal of Hypertension, 27, S5-S10.

Simko F, Pechanova O, Repova Bednarova, et al. (2014). Hypertension and cardiovascular remodelling in rats exposed to continuous light: Protection by ACE-inhibition and melatonin. Mediators of inflammation, 2014 (703175).

Simko F. Pechanova O. Pelouch V, et al. (2010). Continuous light and L-NAME-induced left ventricular remodelling: different protection with melatonin and captopril, "Journal of Hypertension, 28(1), pp. S13-S18.

Swain SM., Whaley FS and Ewer MS (2003). Congestive heart failure in patients treated with doxorubicin: a retrospective analysis of three trials. Cancer, 97 (11), 2869-2879.

Szmit S, Jurczak W, Zaucha JM, et al. (2014). Preexisting arterial hypertension as a risk factor for early left ventricular systolic dysfunction following (R)-CHOP chemotherapy in patients with lymphoma. Journal of the American Society of Hypertension, 8 (11), 791-799.

Tamura EK. Cecon E. Monteiro A.W. et al. (2009). Melatonin inhibits LPS-induced NO production in rat endothelial cells. J. Pineal Res; 46, 268274.

Tengattini S, Reiter RJ, Tan DX, et al. (2008). Cardiovascular diseases: protective effects of melatonin. J Pineal Res; 44, 16-25.

Testa M, Yeh M, Lee P, et al. (1996). Circulating levels of cytokines and their endogenous modulators in patients with mild to severe congestive heart failure due to coronary artery disease or hypertension. Journal of the American College of Cardiology. 28 (4), 964-971.
Toblli JE, Cao G, DeRosa et al. (2005). Reduced cardiac expression of plasminogen activator inhibitor 1 and transforming growth factor $\beta 1$ in obese Zucker rats by perindopril. Heart, 91(1), 80-86.

Volkova M and Russell R (2011). Anthracycline cardiotoxicity: prevalence, pathogenesis and treatment. Curr.Cardiol. Rev; 7, 214-220.

Warpe VS, Mali VR, Arulmozhi S, et al. (2015). Cardioprotective effect of ellagic acid on doxorubicin induced cardiotoxicity in wistar rats. Journal of Acute Medicine, 5(1), 1-8.

Weekley LB (1995): Pharmacologic studies on the mechanism of melatonin-induced vasorelaxation in rat aorta. J Pineal Res; 19(3), 133-8.

Wu Y, Yin X, Wijaya C, et al. (2011). Acute Myocardial Infarction in Rats. J Vis Exp.; (48): 2464.

Yang Y, Sun Y, Yi W, et al. (2014). A review of melatonin as a suitable antioxidant against myocardial ischemia-reperfusion injury and clinical heart diseases. Journal of pineal research, 57(4), 357-366.

Yeung HM, Hung MW, Lau CF et al. (2015). Cardioprotective effects of melatonin against myocardial injuries induced by chronic intermittent hypoxia in rats. Journal of Pineal Research, 58, 12-25.

Yildiz M, Sahin B and Sahin A (2006). Acute effects of oral melatonin administration on arterial distensibility, as determined by carotid-femoral pulse wave velocity, in healthy young men. Exp. Clin. Cardiol, 11, 311-313.

Zhao W, Zhao T, Chen Y, et al. (2008). Oxidative stress mediates cardiac fibrosis by enhancing transforming growth factor-beta1 in hypertensive rats. Mol Cell Biochem; 317, 4350.

Zhou B, Wu LJ, Li LH, et al. (2006). Silibinin protects against isoproterenol-induced rat cardiac myocyte injury through mitochondrial pathway after up-regulation of SIRT1. J. Pharmacol. Sci; 102, 387-395. 


\section{الملخص العربى}

L- اعطاء الميلاتونين مع البيندوبريل يخفف من سمية القلب الناتجة عن دوكسوروبيسين في الفئران التي تعاني من ارتفاع ضغط الدم -بال NAME

\section{تقوى محمد عبد السلام و وسام مصطفى البقلي وأحمد السيد بدوي و 'أمالي حلمي محمد حسنين' و منى حسين رأفت׳}

المقدمة: دوكسوروبيسين هو علاج فعال للغاية للسرطان ولكن له آثار خطيرة على القلب. ويعتبر ارتفاع ضغط الدم أحد عوامل

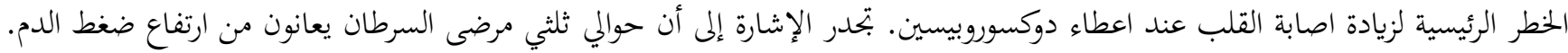

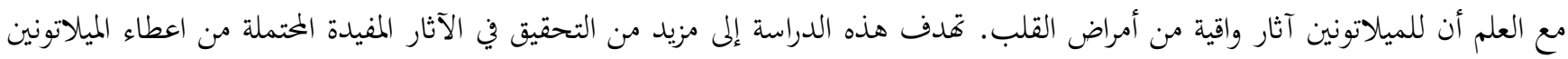
مع البيندوبريل في الفئران المصابة بارتفاع ضغط الدم والمعالجة بدوكسوروبيسين. فرصني.

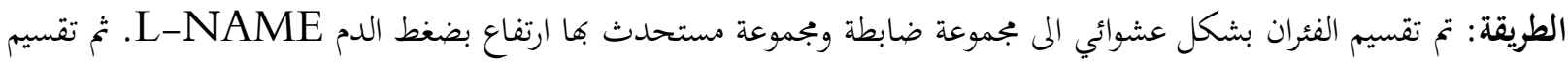
هذه الجموعة باستخدام L-NAME إلى مجموعات فرعية, جمموعة غير معالجة، جمموعة معالجة بدوكسوروبيسين، مجموعة معالجة

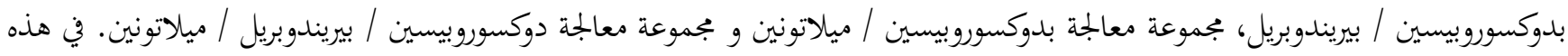

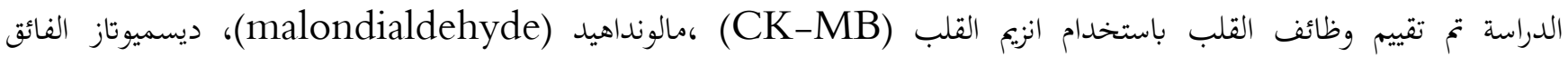
الأكسدة، مؤشر الالتهاب (TNF-

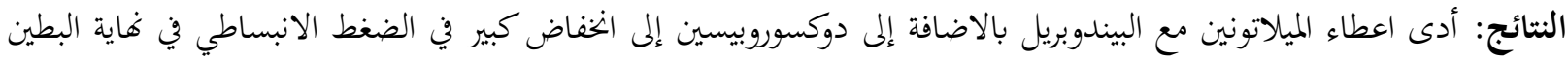

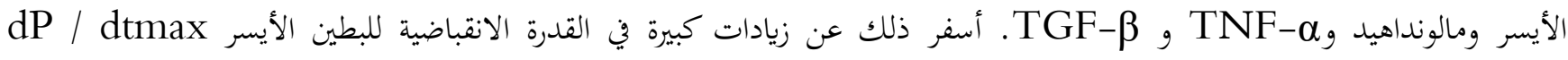

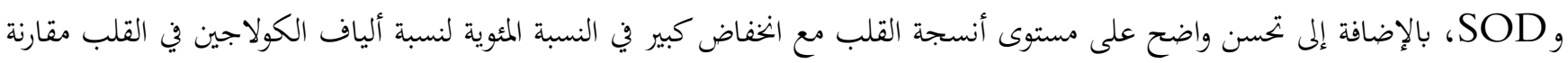
مع استخدام البيندوبريل بمفرده.

الحلاصة: قد أدى اعطاء الميلاتونين مع البيندوبريل في الفئران التي تعاني من ارتفاع بضغط الدم والمعالجون بدوكسوروبيسين الى تقليل

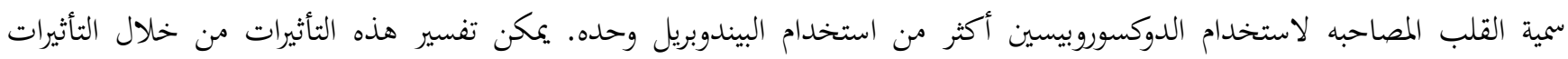
الخافضة للضغط، المضادة للالتهابات، المضادة للأكسدة، والمضادة للتليف المصاحبة لاستخدام المامدام الميلاتونين. 